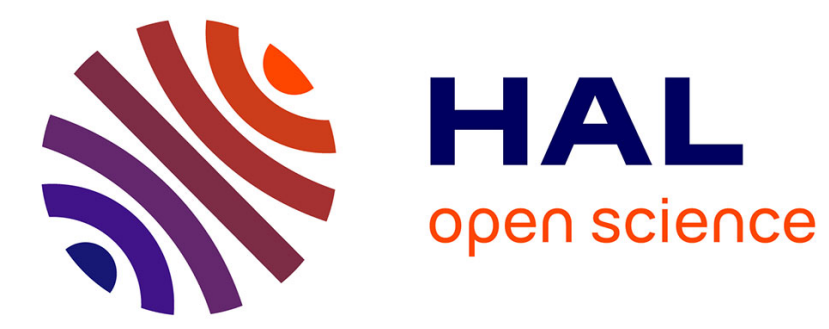

\title{
Gas investigation for laser drilling
}

Matthieu Schneider, Laurent Berthe, Rémy Fabbro, Maryse Muller, Mariette

\author{
Nivard
}

\section{To cite this version:}

Matthieu Schneider, Laurent Berthe, Rémy Fabbro, Maryse Muller, Mariette Nivard. Gas investigation for laser drilling. Journal of Laser Applications, 2007, 19 (3), pp.5. 10.2351/1.2567844 . hal-00794962

\section{HAL Id: hal-00794962 \\ https://hal.science/hal-00794962}

Submitted on 28 Feb 2013

HAL is a multi-disciplinary open access archive for the deposit and dissemination of scientific research documents, whether they are published or not. The documents may come from teaching and research institutions in France or abroad, or from public or private research centers.
L'archive ouverte pluridisciplinaire HAL, est destinée au dépôt et à la diffusion de documents scientifiques de niveau recherche, publiés ou non, émanant des établissements d'enseignement et de recherche français ou étrangers, des laboratoires publics ou privés. 


\title{
Gas investigation for laser drilling
}

\author{
Matthieu Schneidera), Laurent Berthe, Rémy Fabbro, Maryse Muller, and Mariette Nivard \\ Laboratoire pour PIMM (UMR 8006), \\ Arts et Métiers Paristech \\ 151 Boulevard de L'Hôpital 75013 Paris, France
}

\begin{abstract}
This article deals with the gas effect on percussion laser drilling in ms pulse duration range. On the one hand, the flow of assistance gas jet is investigated with and without a target using a strioscopy setup and Pitot's tube. By this way, the position of shock waves in the supersonic jet and near the target surface is revealed. From this characterization, the distance between exit nozzle and target can be optimized to induce higher pressure on surface and protect optics from liquid ejection. On the other hand, metal liquid and vapor jets from irradiated target are observed with a high-speed camera $(100000 \mathrm{Img} / \mathrm{sec})$. Without assistance gas, a surprising result on the video is a shock wave inside the metal vapor jet like a supersonic flow. The assistance gas limits the propagation of the vapor and facilitates the deposition of metallic liquid around the front surface holes.
\end{abstract}

Key words: laser drilling, assistant gas, metallic vapor, chock wave

\section{INTRODUCTION}

Laser drilling in percussion regime is used extensively in aeronautical industries. ${ }^{1}$ This process consists in irradiating metallic targets with a laser tuned in the $\mathrm{MW} \mathrm{cm}^{-2}$ range (pulse duration in $\mu \mathrm{s}-\mathrm{ms}$ range). The laser energy is absorbed by the surface for the heating, the melting, and the vaporization of the target. This vapor spreads out and pushes the melt pool. ${ }^{2,3}$ In this case, the drilling is dominated by melt ejection induced by the pressure gradient between the irradiated area and the hole surrounding.

Today, it is impossible to solve analytically equations which describe this process without introducing some approximations then compromising the accuracy of the final solution. This is why parametric and qualitative studies are essential to achieve the miscorrelation between each component and their own modifications. This allows one to bring out the main parameters, which induce changes in the hole geometry and then capability.

In a previous paper, ${ }^{4}$ the influence on hole geometry of the gas nature and its pressure in nozzle tank have been explored. In the present one, the flow of the assist gas and the modifications induced by a target located in the flow is investigated. With the help of a strioscopy setup, the position of the shock waves in the supersonic jet and near target surface is clearly observed. Nature of the metal vapor jet from irradiated target and the influence of these different flows on the drilling process is discussed using high-speed camera (100 $000 \mathrm{Img} / \mathrm{sec})$ images.

The second part describes experimental setups including HL201P Trumpf laser, jet gas characterization diagnostics (strioscopy and total pressure measurement by Pitot's tube

a)electronic mail : matthieu.schneider@ensam.eu technique), and laser drilling process observation with highspeed camera. The third part presents results and discussions on the influence of the gas on laser drilling process.

\section{EXPERIMENTAL SETUPS}

\section{A. Lasers}

A previous article ${ }^{4}$ showed that the HL201P laser from Trumpf company presents very useful guarantees for a parametric study: A circular "top-hat" intensity distribution in the focal plane, a pulse reproducibility, and a constant focal plane position for any laser parameters. Laser parameters are given in Table I. With a beam analyzer, all

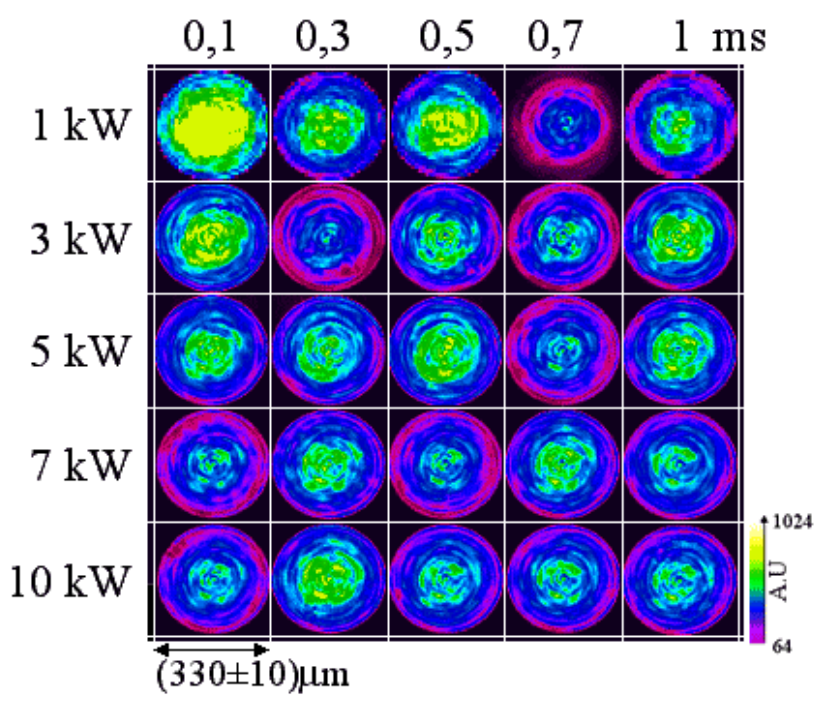

FIG. 1. Intensity distribution at a constant focal plane in function of peak power and pulse duration. 


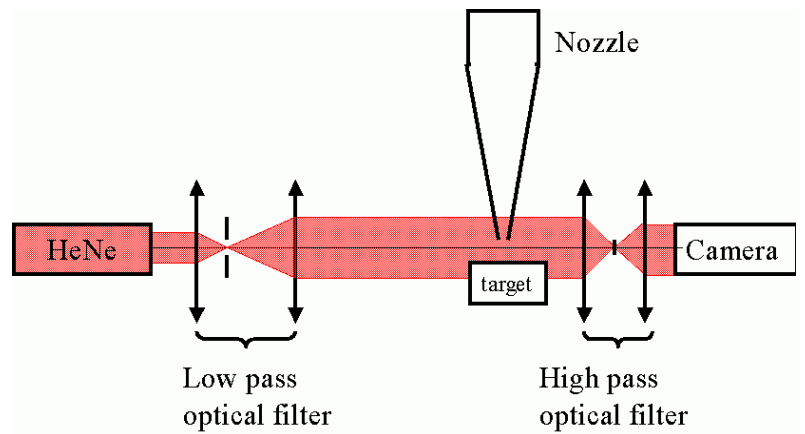

FIG. 2. Schematic representation of strioscopy setup.

these laser properties have been measured. Figure 1 presents the intensity distribution at the focal plane. It is close to a circular top hat for all pulse durations and peak powers tested, especially in the focal plane.

The position of the focal plane is also constant for any peak power and pulse duration. The differences between color codes come from different optical densities which have been used in front of the beam analyser to protect it. The spot diameter is constant too and is equal to $(330 \pm 10) \mu \mathrm{m}$ for all parameters. So, the HL201P allows a circular top-hat intensity distribution, a constant focal plane in accordance with the laser parameters. The HL201P is so stable that the difference between holes is not related to laser beam fluctuations.

\section{B. Setup for gas jet characterization}

A previous paper ${ }^{4}$ has shown that gas is probably the source of many fluctuations of the drilling process. To understand how it works, the observation of gas jet has been performed with strioscopy set up showed on Fig. 2 in a schematic representation.

The principle is well known. The area between the target and the exit of the nozzle is illuminated by a plane monochromatic wave that comes from low pass optical filter. The very little difference of density in the gas flow deviates incident light. The high pass optical filter behind, stops the nondeviated beam and the refracted beam realizes an image on camera. Only the area with different densities will appear on the image; typically the shock wave in compressive flow. Figure 3 presents typical images from strioscopy experience for different nozzle pressures $\left(P_{\text {noz }}\right)$. The line at the top edge corresponds to the exit nozzle. From 2 to 5.6 bars, luminous structure corresponds to stationary shock wave profile in the jet.

Total pressure measurements have been done using a Pitot's tube (Fig. 4). It is a representative laser drilled hole connected to a manometer, which allows the measurement. So, the pressure measured is the spatial average of the scalar
TABLE I. Measured HL201P laser parameters.

\begin{tabular}{lc}
\hline \hline Incident intensity & 1 to $22 \mathrm{MW} \mathrm{cm}^{-2}$ \\
Average power & $201 \mathrm{~W}$ \\
Pulse duration & 0.08 to $1 \mathrm{~ms}$ \\
Frequency & $<1 \mathrm{kHz}$ \\
Energy dispersion & $<1 \%$ \\
Temporal dispersion & $<3 \%$ \\
Diameter in focal plane & $330 \mu \mathrm{m}$ \\
\hline \hline
\end{tabular}

pressure field acting by the gas during the drilling process. From these measurements, pressure profiles are determined like in Fig. 6 as a function of working distance (distance between exit nozzle and target surface $=\mathrm{WD}$ ).

\section{High speed camera observation}

The observation of the laser drilling has been performed with a high speed camera. This camera (Phantom 7, Photon Line), can record a video with a resolution of $128 \times 64$ pixels at 100000 frames per second. For these drilling records no additional lighting is necessary because the drilling process is very shining. Figure 7 presents typical images produced by the high speed camera. Laser comes from the top of picture and the target is located at its bottom. Drilling has been done on Stanley steel.

\section{RESULTS AND DISCUSSIONS}

\section{A. Strioscopy of the free gas jet}

It is well known that the flow becomes supersonic when $^{5,6}$

$$
\frac{P_{\mathrm{noz}}}{P_{\mathrm{amb}}}=\left(\frac{2}{1+\gamma}\right)^{[\gamma /(\gamma-1)]},
$$

where $P_{\text {noz }}$ is the pressure inside the nozzle tank, $P_{\mathrm{amb}}$ is the pressure surround the experimental setup (generally the atmospheric pressure); $\gamma$ is the ratio between the heat capacities.

According to the gas nature, the flow becomes supersonic for different ratio between nozzle pressure and ambient pressure. Table II contains ratios $\left(P_{\mathrm{noz}} / P_{\mathrm{amb}}\right)$ for mono and diatomic which is 2.05 and 1.89 , respectively. Figure 3 presents some strioscopic images as a function of $P_{\text {noz }}$ (from 0 to 5.6 bars) for a diatomic gas. As theory predicts, above $P_{\text {noz }}=2$ bars, the flow becomes supersonic and a shock wave is formed inside the jet. The higher $P_{\text {noz }}$ is, the longer the distance between the first shock wave and the nozzle exit also.

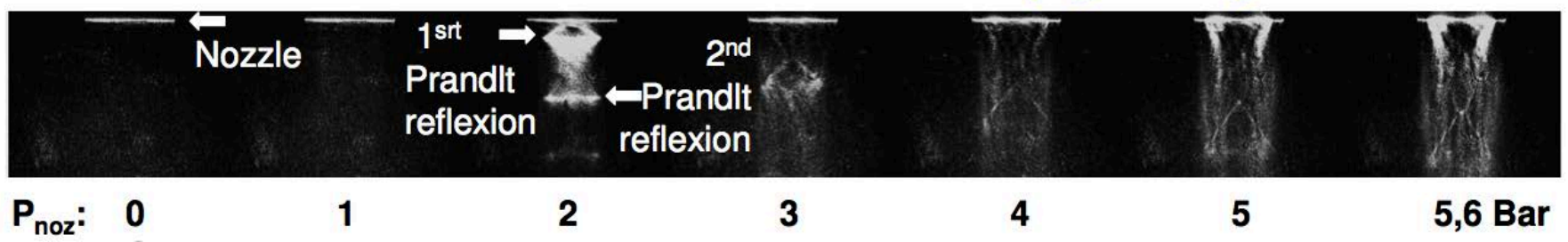

FIG. 3. Strioscopic images of free jet for several nozzle pressures. 


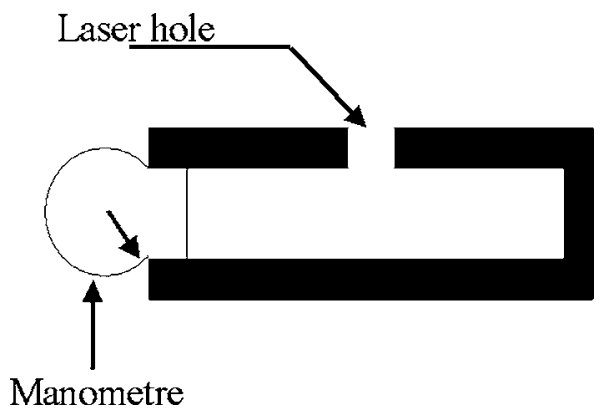

FIG. 4. Scheme of a Pitot's tube.

Besides, these images show that for $P_{\text {noz }}$ above 2 bars, the Mach shock disk (MSD) is missing with this nozzle, only the Prandtl reflections appear. ${ }^{6,7}$ They are generated by some imperfections of the lining nozzle. MSD lack shows that the nozzle is correctly shaped at these pressures. The distance between the Prandtl reflections is constant. So, inside a supersonic free jet some stationary shock waves in the flow are observed.

\section{B. Strioscopy of the gas jet with target}

The gas parameter, which influences the drilling process, is the total pressure on target surface. As Fieret et al. showed $^{7,8}$ that the surface pressure depends on the distance between the exit nozzle and the target surface. Striosopy images can evidence so.

Figure 5 shows pictures performed with strioscopy of the jet with a target surface for WD from 1 to $10 \mathrm{~mm}$. The target is located at the bottom of the images and the nozzle is moved upwards millimeter by millimeter. For this record the $P_{\text {noz }}$ is 2 bars. For any working distance, shock wave is visible near the target surface. Above this shock wave, the jet is still supersonic and below it is subsonic. In comparing Fig. 3 for 2 bars (third picture) and Fig. 5 for $W D=6 \mathrm{~mm}$ (sixth picture) a surface shock wave is generated due to the presence of the target in the jet. Prandtl reflections position is not modified in the jet for constant working distance.

During the moving of the nozzle on Fig. 5, Prandtl's reflections appear one by one and come out from the surface shock wave. For WD 2, 5, 7, and $9 \mathrm{~mm}$ correspond to the emergence of a stationary shock wave from the surface shock wave. For these distances the pressure exerted on the target surface could not be constant.

\section{Pressure on target surface}

Figure 6 presents the total pressure on target surface (and so, on the front of hole during drilling) as function of WD. As shown by Fieret, ${ }^{7,8}$ curves correspond to typical profiles of a jet without MSD. Pressure decreases for WD
TABLE II. Supersonic ratio $\left(P_{\mathrm{noz}} / P_{\mathrm{amb}}\right)$ condition for mono- and diatomic gas.

\begin{tabular}{lcc}
\hline \hline & Monoatomic gas & Diatomic gas \\
\hline $\begin{array}{l}\text { Supersonic } \\
\text { condition } \\
\text { (bar) }\end{array}$ & 2.05 & 1.89 \\
\hline \hline
\end{tabular}

coming from 0 to $3.5 \mathrm{~mm}$. Above this distance, pressure oscillate with a maximum every $3 \mathrm{~mm}$ due to the emergence of the Prandtl reflections shock waves. Their amplitude (maximum minus minimum) decreases with increasing of WD (1.2 and 0.5 bars for the first oscillation at $5 \mathrm{~mm}$ and last one at $18 \mathrm{~mm}$, respectively). The mean pressure is close to 2.5 bars. These profiles are independent of the gas nature (argon and oxygen). On Fig. 6, the pressure can be reduced about only one third (compared to the pressure for $\mathrm{WD}=0$ : 4 bars) for the working distance below $10 \mathrm{~mm}$. The precision on the positioning, to get a determined pressure on the target surface, is not less than one millimeter corresponding to the distance between a maximum and a minimum.

During the process, ejected liquid can modify the exit nozzle and so pressure profile on target which is very sensitive to nozzle shape. ${ }^{7,8}$ Consequently, a good protection of exit nozzle from degradation or/and a regular nozzle characterization are primordial. For example, for the present experiment, to protect optics and nozzle and to ensure a constant pressure on target, a working distance higher than $10 \mathrm{~mm}$ could be quite a good compromise.

\section{Drilling without gas}

\section{Description of the vapor}

Figure 7 shows a video sequence with the high speed camera. On the first line, images are presented every $10 \mu \mathrm{s}$. The time origin is the first image for which luminosity occurs. So, at this moment, the irradiated area target is vaporized and the vapor pressure is above atmospheric pressure. ${ }^{2}$ Until $20 \mu$ s the vapor expands in the atmosphere and the gas velocity is in the range of $50 \mathrm{~m} \mathrm{~s}^{-1}$.

At $30 \mu$ s (image 4) we see the beginning of a structure construction in the flow and the velocity is now in the range of $100 \mathrm{~m} \mathrm{~s}^{-1}$. At $40 \mu \mathrm{s}$ the structure clearly appears: A MSD is generated clearly in the metal vapor. Moreover, the jet becomes very directional.

As seen previously in Sec. III A, the vapor behaves like the assist gas and the drilled hole play the role of a nozzle. When the ratio between pressure in the hole and pressure around becomes higher than 2.05 bars the flow becomes supersonic; with the hypothesis that the vapor is a

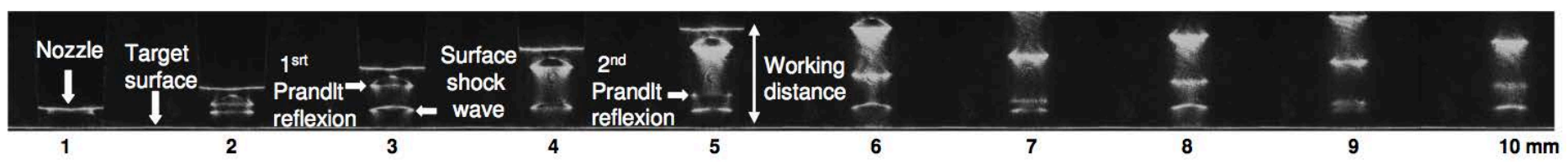

FIG. 5. Strioscopic images of the target surface for several working distances (WD) in millimeters with a 2 bars nozzle pressure. 


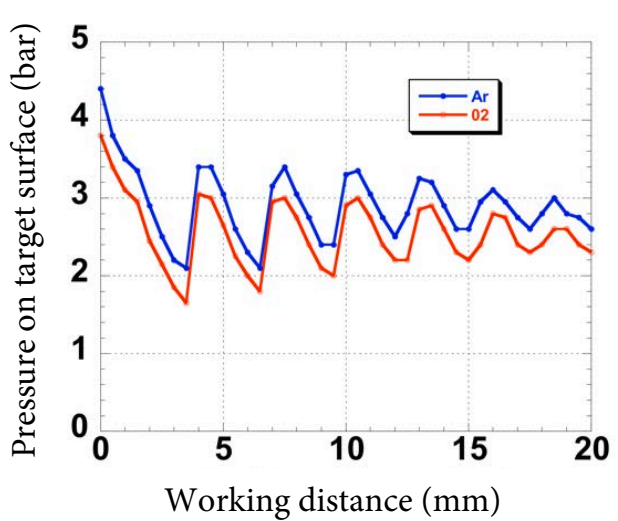

FIG. 6. Pressure on target as function of working distance between the exit nozzle and the target surface (called WD) for a 3.5 bars nozzle pressure for argon and oxygen gas.

monoatomic gas. At this moment, the jet becomes directional and a shock wave structure appears inside it. After $100 \mu \mathrm{s}$ the whole structure starts to embed into the target and reduces its width size.

\section{Description of the melt ejection}

At $40 \mu$ s on Fig. 7, the liquid ejection begins. Its starts almost horizontally. Indeed, the process is not stationary, and the bottom of the hole is still closed to the surface. Liquid jet becomes vertical between 300 and $400 \mu \mathrm{m}$ when the hole is deeper. In fact, the wall of the hole directs the melt ejection quite vertically. After $400 \mu$ s when the drilling becomes deep the flow of melt ejection is discontinuous but still very vertical.

\section{E. Drilling with an assist gas}

With an assist gas, two supersonics jets are opposed to each other.

Figure 8 shows images from a sequence record with the same camera and experimental conditions except the assist gas pressure which is 3 bars on target surface.

\section{Description of the vapor}

The presence of an assist gas stops the vapor expansion above the surface shock wave.

Only up to $30 \mu$ s (image 4), a MSD is generated is the metal vapor. Up to $40 \mu \mathrm{s}$, the vapor shock wave grows in strength but the pressure is not high enough to cross the shock wave induced by the assist gas. The vapor is trapped between the assist gas shock wave and the target surface. It escapes only by the sides and so is not as directional as without gas. Moreover, the hot vapor in this configuration can fall to the target surface and so melt it. At $400 \mu \mathrm{s}$, the vapor is ejected only through the rear of the target by the surface pressure after the opening of the hole.

\section{Description of the melt ejection}

Unlike the vapor, the assist gas does not stop the melt. It just slows it down to the target surface. Figure 9 shows two holes performed with (a) and without assist gas (b). The hole on Fig. 9(a) is produced with 3 bars surface pressure, and the hole on Fig. 9(b) with no gas. Clearly, lot of metal deposition on surface is evidenced around the hole drilled with assistance gas but not for other one without gas.

Concerning the breaking through occurring at $400 \mu \mathrm{s}$ (Fig. 8), the pressure inside the hole ejects the melt pool through the front and rear hole. However, the gas on the surface penetrates inside the hole and pushes the melt pool through the rear target. Consequently, there is no more melt ejection by front hole at that time as seen on pictures up to $500 \mu \mathrm{s}$. This observation confirms the ejection of liquid through the rear hole. In the case of applications, this melted metal could pollute a clearly opposite part.

\section{SUMMARY}

This paper presents gas investigation in laser drilling based on assistance gas characterization and high speed camera observations. Working distance can be optimized to apply high pressure on surface target and to protect optics from liquid ejection during the drilling.

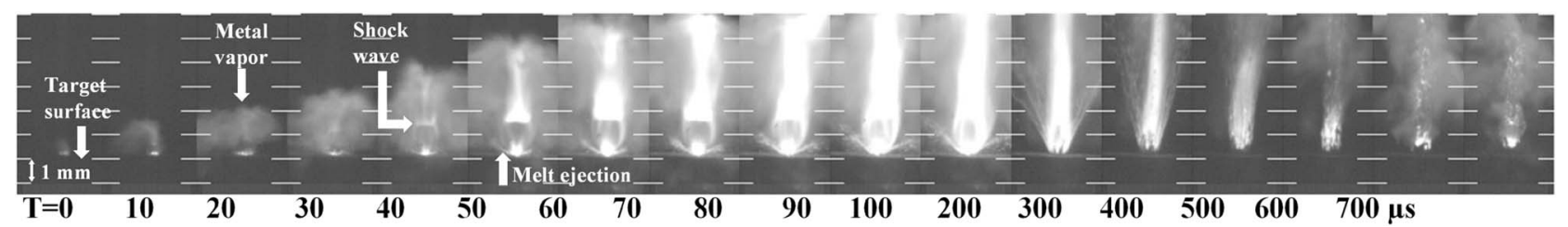

FIG. 7. Video acquisition of laser drilling without gas at $10^{5}$ frames per second (peak power: $16 \mathrm{Kw}$, pulse duration: $1 \mathrm{~ms}$ ).

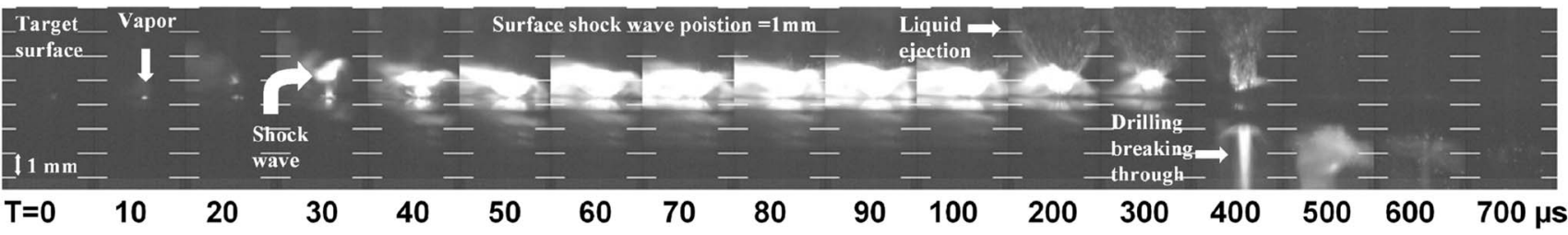

FIG. 8. Video acquisition of a breaking through hole with assist gas (pressure on the surface: 3 bars) at $10^{5}$ frames per second. Peak power: $16 \mathrm{~kW}$; pulse duration: $1 \mathrm{~ms}$. 


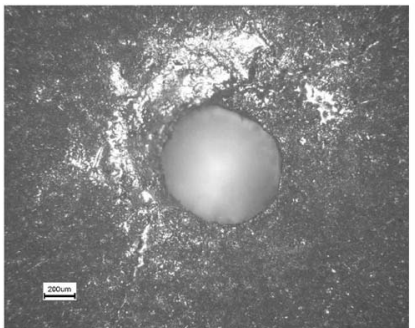

(a)

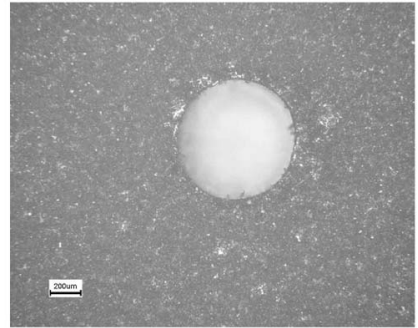

(b)
FIG. 9. Two front holes: (a) Drilled with assistance gas (pressure on the surface: 3 bars) and (b) without gas. Peak power is $16 \mathrm{~kW}$ and pulse duration is $1 \mathrm{~ms}$.

Finally, there are two reasons to use gas for drilling. First, for the optics protection from metallic melt ejections and, secondly, to improve drilling quality when drilling break through occurs. ${ }^{4}$

However, the gas has some drawback effects: A trapping of the metal vapor, which is locked up below the surface shock wave; a slowdown of the ejected scories; a modification of the target surface around the front hole.

From these results, the usual gas parameters for percussion laser drilling in application could be reconsidered to higher working distance and lower pressure applied.

\section{ACKNOWLEDGMENTS}

The authors thank Trumpf Compagny for HL201P laser facilities, Photonlines for high speed camera facilities, and CEA (Commissariat à l'Energie Atomic) and CNRS (Centre National pour la Recherche Scientifique) for financial support.

${ }^{1}$ C. A. McNally, J. Folkes, and I. R. Pashby, "Laser drilling of cooling holes in aeroengines: state of the art and future challenges," Mater. Sci. Technol. 20, 805-813 (2004).

${ }^{2}$ S. I. Anisimov and V. A. Khokhlov, Instabilities in Laser-Matter Interaction (CRC Press, Boca Raton, 1995).

${ }^{3} \mathrm{~V}$. V. Semak and A. Matsunawa, "The role of recoil pressure in energie balance during laser materials processing," J. Phys. D 30, 2541-2552 (1997).

${ }^{4}$ M. Schneider, R. Fabbro, L. Berthe, L. Landais, M. Nivard, and P. Laurens, Parametric study of drilling with new innovative laser source: application to percussion regime, Proc. Intnl. Congrs. on Appl. on Application of Lasers and Electro-Optics (ICALEO'04), San Francisco, 2004, pp. $540-546$.

${ }^{5}$ L. D. Landau and E. M. Lifshitz, Mécanique des fluides $2^{\mathrm{EME}}$ ED T6. (1989).

${ }^{6}$ E. A. Brun, A. Martineau Lagarde, and J. Mathieu, Mécanique des fluides $2^{\mathrm{EME}}$ Ed. (1968).

${ }^{7}$ J. Fieret, M. J. Terry, and B. A. Ward, "Aerodynamic interaction during laser cutting," SPIE laser processing: Fundamentals, Applications, and Systems Engineering, Vol. 668 (1986), pp. 53-62.

${ }^{8}$ J. Fieret and B. A. Ward, "Circular and non-circular nozzle exits for supersonic gas jet assist in CO2 laser cutting," Proc. 3rd Intl. Conf. on Laser in Mfg (LIM3), Paris, 1986, pp. 45-54. 